\title{
Event related potentials (ERPs) and alpha waves in cognition, aging and selected dementias: A source of biomarkers and therapy
}

\author{
Priya Miranda ${ }^{1}$, Christopher D Cox ${ }^{2}$, Michael Alexander ${ }^{1}$, Slav Danev $^{3}$ and Jonathan Lakey ${ }^{1 *}$ \\ ${ }^{1}$ Department of Surgery and Biomedical Engineering, University of California Irvine, California, USA \\ ${ }^{2}$ Department of Neurology, David Geffen School of Medicine, University of California, Los Angeles, California, USA \\ ${ }^{3}$ Medeia Inc, Santa Barbara, CA, USA
}

\begin{abstract}
In $2010,8 \%$ of the world's population was $>65$ years of age. The prevalence of dementia in 2015 was 47.47 million, while its incidence was at 7.7 million new cases each year i.e. translates to a new case every 4.1 seconds. Alzheimer's contributes to $60-70 \%$ of cases with dementia. The current global costs of care for dementia is US $\$ 604$ billion/ year. One of the keep obstacles to better treatment outcomes and quality of life is late diagnosis. The present paper covers the role of EEG-based Alpha waves and event-related potential (ERPs) components as biomarkers of cognition and the changes in their features with aging, dementia, and Alzheimer's.
\end{abstract}

\section{Introduction}

\section{Normal aging and dementia}

Epidemiological studies on normal aging and dementia revealed that in 2010 there were 524 million individuals $>65$ years of age. This accounted for $8 \%$ of the world's population in 2010 . The projections for 2050 are that this number is expected to rise to 1.5 billion individuals $>65$ years and will account for $16 \%$ of the world's projected population [1]. Further alarming statistic is that between 2010 and 2050, the number of older people in less developed countries will increase by $250 \%$ as compared with a $71 \%$ increase in developed countries [1].

Prevalence of dementia in 2015 was 47.47 million, with 75.63 million and 135.46 million being the projected estimated for 2030 and 2050 respectively [2-6]. Incidence of dementia is 7.7 million new cases each year i.e. translates to a new case every 4.1 seconds. $5 \%-8 \%$ of individuals $>65$ age, $15 \%-20 \%>75$ age, and $25 \%-50 \%$ of individuals $>85$ age have dementia. Alzheimer's disease (AD) or senile dementia of the Alzheimer's type (SDAT) contributes to $60-70 \%$ of cases with dementia [1-6].

The implications are that not only infrastructure in terms of health care systems and health care givers need to be up-scaled to meet future needs but that globally systems need to be set in place that can ensure we meet the cost of care. Factors influencing costs include; the cost of providing health and social care to the aged and individuals with dementia, effect on the work force in terms both care givers and younger individuals with early dementia and the effect on the family in terms of loss of income/reduction in income for both care givers and younger individuals with early dementia. Current global costs of caring for people with dementia are US\$ 604 billion/ year and the projected global estimates is US\$ trillion in 2050 [1-6]. Taken together one can appreciate the significant impact of dementia on the global population.

\section{Electrophysiological studies on cognition}

While $\mathrm{AD}$ accounts for $60-70 \%$ of cases with dementia its clear-cut diagnosis from the other types of dementias namely; normal age-related dementia, frontotemporal lobar degeneration, vascular dementia, dementia with Lewy bodies, Parkinson's disease dementia, CreutzfeldtJakob disease etc requires extensive and expensive clinical and neurological examination and testing [1-8]. Diagnosis and classification of dementia is based on the DSM-5 following a thorough neuro-clinical examination and neurophysiological testing using established tests like the Mini-Mental State Examination (MMSE), Montreal Cognitive Assessment (MoCA), the Clinical ,Dementia Rating Scale (CDRS), Ischemic Scale (HIS) and the Instrumental and Basic Activities of Daily Living (IADL, BADL) [9-15]. Individuals whose scores fall within -1 to -2 standard deviation (SD) range (between the $3^{\text {rd }}$ and $16^{\text {th }}$ percentiles) are diagnosed as having mild cognitive impairment and those with scores below -2SD or $3^{\text {rd }}$ percentile major/severe cognitive impairment [9-15].These tests are either form-based or computer-based and may require either a clinician or trained technician and in some instances the patient themselves to fill out the test. The drawback of the tests is that a patient with early MCI may still be able to complete the test quite successfully and thus remained undiagnosed and untreated.

One of the reasons attributed to failure of AD-modifying drugs has been that individuals are diagnosed in advanced stages of the disease [16-22]. In the search for a universal gold standard for diagnosis for

*Correspondence to: Jonathan RT Lakey, Department of Surgery, 333 City Blvd West, Suite 1600, Orange, CA 92868, Tel:1-949-824-8022; Fax:1-714-456-6188; E-mail: jlakey@uci.edu

Received: October 01, 2019; Accepted: October 17, 2019; Published: October 25,2019 
AD several challenges still exist [16-22]. Cerebrospinal fluid (CSF) biomarkers include amyloid-beta $(\mathrm{A} \beta 42)$ whose levels correspond to amyloid plaque levels in the brain and phosphorylated tau (p-Tau) are capable of differentiating AD dementia, $\mathrm{MCI}$ due to normal aging, and non-AD dementia [16-22]. Some of the drawbacks include; the tests are expensive and highly invasive, as CSF is obtained via a lumbar puncture [16-22].

In contrast the EEG is relatively inexpensive and electrophysiological biomarkers obtained from ERPs and brain waves (alpha, beta, theta, and gamma: frequency, amplitude, power etc) could possibly serve as screening and/or diagnostic tools depending on their sensitivity, specificity and accuracy [23]. Electrophysiology (EEG) based tests of cognition have the ability to pick up early changes in brain wave rhythms even prior to biochemical testing and neuroimaging [1-15]. Due to their cost, the duration and complexity of data interpretation and their cumbersome and temporal nature EEGs were earlier not popular as diagnostic tools. However developments in the field have resulted in more affordable, office-based and/or portable systems. Today's EEG machines are capable of not only recording and evaluating brainwaves (alpha, beta, gamma, delta), evoked potentials and event related potentials (ERPs) but of quantifying and creating 2-D topographical color-coded brain maps comparing a patient's brain function to a normative database via Quantitative EEG (QEEG), as well as using Low Resolution Electromagentic Tomography (LORETA) where 2-D EEG data is converted into 3-D data to source locate EEG waves down to the cortical areas/Brodmann Areas (BA) they originate from [24-26].

A key feature of normal aging, pre-senile and $\mathrm{AD}$ is neuro-cognitive impairment. The domains related to cognition as stipulated by DSM5 include: complex attention executive abilities learning/memory, language, visuoconstruction, visuoperception and social cognition [9]. EEG parameters pertinent to cognition include i) thalamic generated alpha waves (posterior alpha peak frequency) and ii) event related potentials (ERPs) components. These 1-D electrophysiological parameters are converted to 2-D QEEG maps to determine power, coherence and connectivity, 2-D data is then converted to 3-D data via source location of alpha waves or ERP's using LORETA to locate the Brodmann areas (BA) involved is [23-26].

\section{Event-related potentials (ERPs) and cognition}

Evoked or event-related potentials (ERPs) (Figures 1a-d) are obtained following an event/stimulus (visual, auditory, motor or task). Figure 1b, Figure 1c and Figure 1d shows the ERP components obtained using NeuralScan by Medeia, a state-of the-art computer-based EEG computer-based system. If for example, the neuro-electrophysiological test lasts 10-minutes and the stimuli is repeated every 30 seconds with a 10 second delay before the next cycle then each epoch that capture one complete stimuli and response cycle are marked out and selected during the EEG recording lasting 10-minutes. The averaged response gives the event-related potential (Figure 1b) for that stimulus. ERP's obtained after resting-state EEG (eyes closed and opened, Figure 1c), or following a specific task to evaluate working memory or from evoked potentials (visual, auditory, odd ball paradigm) or following behavioral motor tests as used to assess the cognitive status. Table 1 provides a concise and comprehensive snapshot of the ERP components, the features pertinent to cognition that they reflect or are elicited by and their source location on the respective Brodmann areas (BA) [27-72]. Provided below are the pertinent definitions.

\section{ERP component - definitions [27-72]:}

- "P" and "N" denote the positive and negative nature of the ERP components. The number eg: P100 or N100 indicates the latency.

- Peak amplitude: the difference between the mean prestimulus baseline and maximum peak amplitude.

- Peak latency: the time point corresponding to the maximum amplitude and calculated relative to stimulus onset.

- P50: defined as the maximum positivity between 24 and $72 \mathrm{~ms}$ poststimulus

- P100: maximum negativity between 65 and $90 \mathrm{~ms}$

- N100: maximum negativity between 70 and $130 \mathrm{~ms}$

- P200 the maximum positivity between 180 and $235 \mathrm{~ms}$ (measured for standard and target), and

- N200the maximum negativity between 205 and 315 ms (for target tones).

- The P3a was defined as the maximum positivity between 325 and $500 \mathrm{~ms}$ (for the distractor), and the

- $\mathrm{P} 3 \mathrm{~b}$ as the maximum positivity between 325 and $580 \mathrm{~ms}$ (for target tones). P3b amplitude is determined by the amount of attentional resources allocated when working memory is updated

- Slow wave: maximum negativity between 460 and $680 \mathrm{~ms}$ (for target tones). Related to the P3b, or classic P300. It is elicited when a deviant stimulus is associated with a task and reflects an update in working memory. (Table 2)

\section{Event-Related potentials (ERPs) and cognitive impairment in normal aging and dementia}

P50 is generated by the primary and secondary auditory cortices [73]. It is an exogenous cognitive process [74]. It exhibits sensory gating at early sensory stage [75]. Its amplitude is modulated by frontal brain regions thus unrestrained P50 amplitudes as seen in AD are thought to indicate functional disconnection of the prefrontal cortex i.e. it no longer modulates the auditory cortical response [76,77]. Another unique feature is that $\mathrm{P} 50$ amplitudes increase in early $\mathrm{AD}$ and return to normal levels in advanced stages. The reason for this pattern is that $\mathrm{AD}$ in its initial stages attacks inhibitory mechanisms that restrain the P50, in its advanced stages $\mathrm{AD}$ impair sensory cortical areas that generate P50 [78-80]. P50 amplitude at C3 in response to standards was found to be the best predictor, with $94.7 \%$ sensitivity, $94.1 \%$ specificity, and total model accuracy of $94.4 \%$. P50 amplitude was also found to be a significant predictor of CSF amyloid positivity status (Figure 3) [81].

A 5-year follow-up study on auditory sensory (P50, N100) and cognitive potentials (P300) carried out on amnestic MCI $(n=41), A D(n=14)$, and younger $(n=22)$ and age-matched older controls $(n=44)$ showed P50 amplitude and P300 latency increased with normal ageing and the increase was further visible in individuals with $\mathrm{MCI}$ and $\mathrm{AD}$ [82]. Two other studies using auditory evoked potentials to elicit P50, N100, P200, N200, P300 one using elderly controls $(n=12)$ and MCI $(n=15)$ and the other using age-matched controls $(n=16)$ and MCI $(n=17)$ in a passive listening paradigm with stimulus presentation rates of $2 / \mathrm{s}, 1 / 1.5$ $\mathrm{s}$ and $1 / 3 \mathrm{~s}$ also had similar findings. Amplitudes of the middle-latency components $(\mathrm{Pa}, \mathrm{Nb}, \mathrm{P} 1$ peaking at approximately 30,40 , and $50 \mathrm{~ms}$, respectively) did not differ between groups, but a slow wave between 30 and $49 \mathrm{~ms}[76,82,83]$. 
Neuralscan

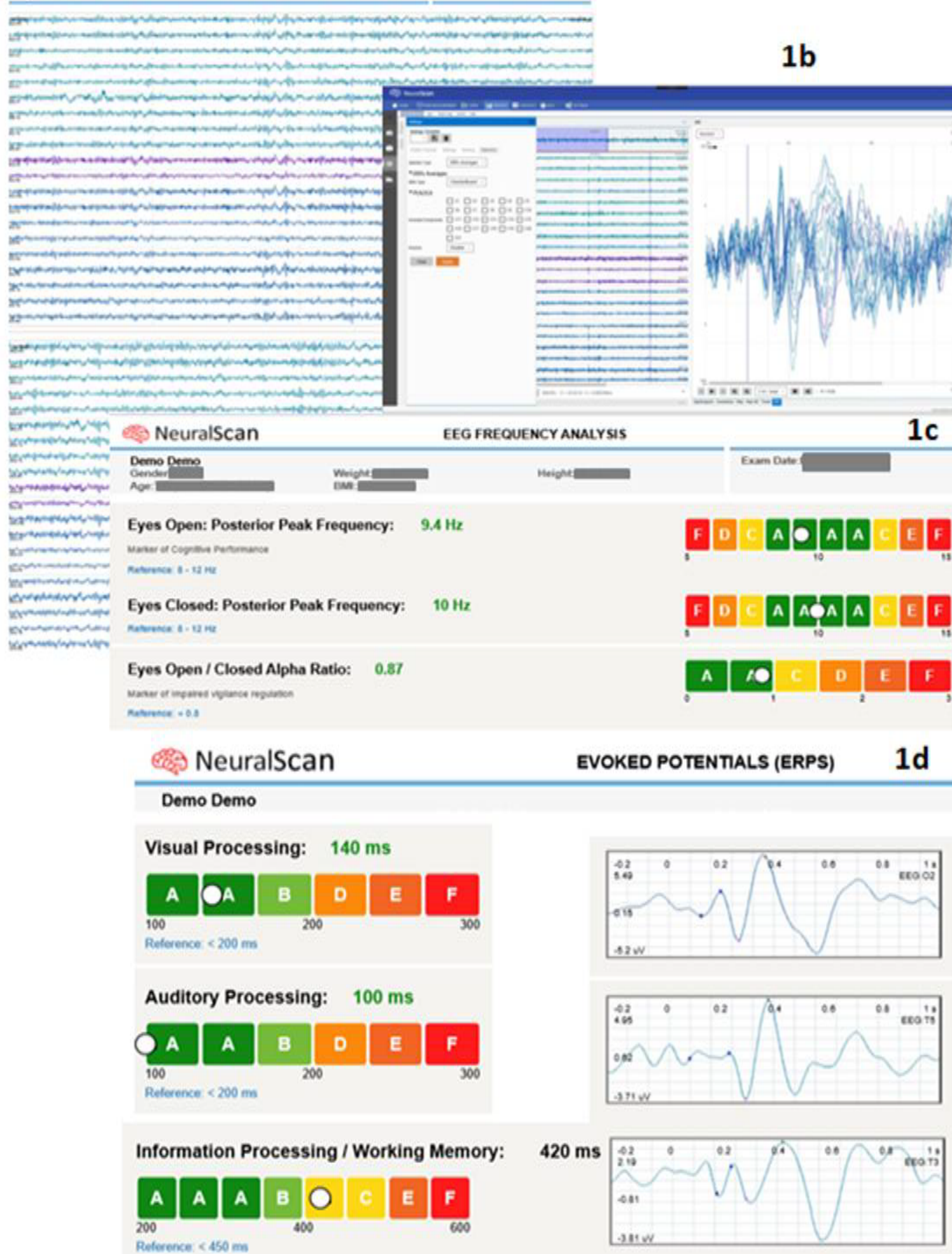

A terence $<450 \mathrm{~mm}$

Normal P300 latency under go-nogo conditon and neuronal capacily associated with attenbon and intormation processing:

Figure 1. 1a) EEG recording obtained during "Eyes Closed" condition using NeuralScan by Medeia, 1b) ERP averages, elicited using the Checkerboard test using NeuralScan by Medeia, 1c) EEG Frequency analysis carried out using NeuralScan by Medeia to capture and calculate Posterior Peak Alpha frequency (Eyes Closed and Eyes Open) and the ratio of Peak Alpha frequency Eyes Closed: Eyes Open and 1d) Visual, Auditory and Information processing/Working Memory Evoked Potentials captured and quantified using NeuralScan by Medeia 
Table 1. ERP Components - Potential Biomarkers of Cognitive Ability

ERP components Short-latency [27]: Exogenous Cognitive Processes [27] (i.e. modulated by the physical attributes of the stimulus) involved in attention selection mechanisms [28]

P100 [29-31] Early sensory processing of attended stimuli

N100 [29-31] Early stage of orienting of attention towards task-relevant target stimuli
- Posterior visual P100: fusiform gyrus [32]

- Anterior P100: frontal generators [35]

- Generated by distributed dipoles in lateral extra-striate cortex with contribution from parieto-occipital and occipito-temporal areas [33,34]

- Anterior N100 result from frontal generators [35]

Mid-latency [27]: Exogenous Cognitive Processes [27] involved in Attention selection mechanisms [28]

\begin{tabular}{|c|c|c|}
\hline $\mathbf{P 2 0 0 / P 2 a}$ & $\begin{array}{l}\text { - } \\
\text { - Reftention modulation process in oddball paradigms [36] } \\
\text { - } \\
\text { Discrimination processes [38] Selectively responsive/ Evaluates \& hierarchically selects task } \\
\text { relevance of presented visual stimuli for further processing }\end{array}$ & Orbito-frontal cortex [39-42] \\
\hline $\mathbf{N} 200 / \mathbf{N} 2 \mathbf{b}$ & $\begin{array}{l}\text { - Categorization, perceptual closure, and attention focusing, ultimately signaling formation of } \\
\text { - } \begin{array}{l}\text { a perceptual representation. [43-44] } \\
\text { secorded from fronto-central and centro-parietal scalp locations between } 180-320 \text { ms post- } \\
\text { stimulus [43-44] Response to conflict detection /Inappropriate response inhibition [45-46] }\end{array}\end{array}$ & Anterior cingulate cortex (ACC) and prefrontal sources [47] \\
\hline
\end{tabular}

Long-latency [27]: Endogenous Cognitive Processes [27] involved in Organization and interpretation of stimulus [28]

P300

- Obtained in an oddball paradigm [48-49]; Novel targets elicit a fronto-central P3a response

[50] and Rare targets elicit a centro-parietally P3b [50]

- In 3-stimulus oddball task\#

- P3a: "orients" to novel distracters; P3b ability to sustain attention to target

- P3a : fronto-central hippocampus, medial and inferior frontal, dorsal PFC and anterior cingulate cortex [50-55]

- P3b: centro-parietall, hippocampus, parahippocampal areas, insula, temporal lobe, occipital cortex, and thalamus. [56-61]

Error-related Potentials : Cognitive Processes involved in error monitoring, error recognition, and subsequent posterior response correction

- Emerging between 40-150 ms following an incorrect behavioral response/a commission error [62]

Error-related negativity $\quad$ ERN reflects an initial automatic brain response as a result of an error [63-65]

$\begin{array}{lll}\text { (ERN / Ne) response } & \text { ERN is associated with self-monitoring of behavior (i.e. self-correction and posterior slowing }\end{array}$ responses) [63] and biomarker of error processing [63-65]

- ACC involved in self-monitoring \&guiding attention in goal-directed actions [62-65]

Error-Related positivity $\bullet$ Conscious recognition of the error [63]

Error-Related positivity - Attribution of motivational significance to the committed error, [62-64,68-71]
(Pe) [54]

- Conscious reflection and comprehension of the error [62-64,68-71]

- Caudal ACC [66-69,72]

- Anterior cingulate cortex (ACC) provides an interface between frontal action selection processes, limbic emotion or motivation processes, and motor output regulation [65-67]

Rostral ACC division [66-69,72]

\# Oddball paradigm: wherein two stimuli are presented in a random order, one of them frequent (standard) and another one rare (target). Eg: horizontal and vertical stripes and then checkerboard with fixation dots to evaluate focused attention. A modification of the task: a third, also infrequent novel distracter is presented along with the standard and rare target stimuli.

Table 2. ERP components in Normal Aging, MCI and AD

\begin{tabular}{|c|c|c|c|c|}
\hline ERP feature & Elicited/Engaged in & Reflects & Latency (ms) & Amplitude $(\mu V)$ \\
\hline P50 & Exogenous sensory processes & $\begin{array}{l}\text { Increases in Normal ageing } \\
\text { Additional increase in MCI.and AD }\end{array}$ & $\begin{array}{c}\text { 5-year follow-up study: Increases in normal } \\
\text { ageing. Significantly increased in MCI } \\
{[76,82,83]}\end{array}$ & $\begin{array}{c}\text { 5-year follow-up study: Increases in } \\
\text { normal ageing. Significantly increased } \\
\text { in MCI } \\
\text { MD > than SD and MCI-convert }>\text { MCI- } \\
\text { stable. golob significantly increased in } \\
\text { MCI }[76,82,83]\end{array}$ \\
\hline N100 & $\begin{array}{c}\text { Bottom-up information such } \\
\text { as stimulus characteristics } \\
\text { attention and memory-related } \\
\text { variables [87-89] }\end{array}$ & $\begin{array}{l}\text { Prefrontal cortex and the nucleus basalis } \\
\text { modulate auditory cortical responses to } \\
\text { sound }[76,82,83]\end{array}$ & & $\begin{array}{c}\text { Declines in AD. Changes in regulatory } \\
\text { inputs from brain regions that are involved } \\
\text { in higher cognitive processes (attention } \\
\text { and memory deficits } 46 \text { ) directly affected } \\
\text { by early MCI. }[85,89]\end{array}$ \\
\hline N200 & $\begin{array}{c}\mathrm{N} 2 \mathrm{a} / \text { mismatch negativity } \\
(\mathrm{MMN}) \text { and } \mathrm{N} 2 \mathrm{~b} \text {, represents } \\
\text { short duration memory } \\
\text { functions and preattentive } \\
\text { storage [91] }\end{array}$ & $\begin{array}{c}\text { Cognitive processes of stimulus } \\
\text { identification and distinction [92] } \\
\text { temporal cortex, frontal lobe, thalamus and } \\
\text { hippocampus generate MMN [92]. frontal } \\
\text { and the superior temporal lobe generate } \\
\text { N2b [41] }\end{array}$ & $\begin{array}{l}\text { Increases in AD32 Correlates with changes in } \\
\text { executive function and attention }[85]\end{array}$ & Declines in AD [85] \\
\hline P300 & $\begin{array}{c}\text { Elicited by auditory, visual, } \\
\text { olfactory or somatosensory } \\
\text { stimuli } \\
{[76,82,83,85,90]}\end{array}$ & & $\begin{array}{c}\text { Increases with normal aging and } \\
\text { Sex related differences seen (chinese } \\
\text { 5-year follow-up study: significantly increased } \\
\text { in MCI }[76,82,83]\end{array}$ & \\
\hline P3a & Focal attention [87- 89] & $\begin{array}{c}\text { Engagement of attention and processing } \\
\text { of novelty }\end{array}$ & $\begin{array}{l}\text { Orientation to a nontarget deviant stimulus } \\
\qquad[92,93]\end{array}$ & $\begin{array}{l}\text { Positively correlated with executive } \\
\text { function }[95,93] \\
\text { Declines in AD associated with decreased } \\
\text { attention and executive function }(95,93)\end{array}$ \\
\hline P3b & $\begin{array}{l}\text { When deviant stimulus is } \\
\text { associated with a task }\end{array}$ & update in working memory $[93,95]$ & $\begin{array}{c}\text { amount of attentional resources allocated when } \\
\text { working memory is updated [94] } \\
\text { Increases in AD [95] }\end{array}$ & $\begin{array}{l}\text { amount of attentional resources allocated } \\
\text { when working memory is updated [96] } \\
\text { Declines in AD (95) }\end{array}$ \\
\hline Slow Wave & Negative deflection after P3b & Final stage of stimulus evaluation & $\begin{array}{c}\text { Increases in AD [95] } \\
\text { Latency is affected by task difficulty and ease of } \\
\text { categorizing events [97] }\end{array}$ & $\begin{array}{l}\text { Amplitude correlates positively with task } \\
\text { demands and inversely with stimulus } \\
\text { detection accuracy, }\end{array}$ \\
\hline
\end{tabular}


The P300 (Table 3) is elicited by auditory odd ball paradigm aimed at discriminating between a standard, target and distracter tone wherein auditory cortical activity is used to distinguish amnestic MCI and dementia [82,83]. The P300 and N200 are ERP biomarkers currently in clinical trial. In a clinical study on 30 subjects with $\mathrm{AD}, 20$ with MCI and 10 HC P300 latencies differed significantly between the groups $(\mathrm{p}<0.001)$ and the diagnostic ability was: sensitivity $87 \%-95 \%$, specificity $90 \%-95 \%$ (for prolonged P3 latencies) and sensitivity $70 \%$ $75 \%$, specificity 70\%-90\% (for prolonged N2 latencies) [84].

The ERP word repetition paradigm is an odd ball paradigm aimed at recording verbal ERPs aimed at eliciting the $\mathrm{N} 400$ and the late positive component (LPC) P600 are useful to assess verbal episodic memory processes [85]. N400 amplitude is small for semantically "congruous" words/contexts, repetition of words in lists of unrelated items or in normal conversation, but large for semantically "incongruous" words/ contexts. The P600/LPC recorded in left temporal channels between 400 and $1000 \mathrm{~ms}$ following a stimulus. The medial temporal lobe is associated with declarative memory (binding item with context). Abnormality/Decline in latency and amplitude indicate a 87 to $88 \%$ conversion rate to dementia while HC have a $11-27 \%$ chance of conversion $[85,86]$.

Table 2 provides a brief overview of the ERP components in normal aging, MCI and AD [76-97,98]. Figure 2 and Figure 3 present results of three published studies on ERP components, normal aging, MCI and AD clearly illustrating the diagnostic ability of ERP components in distinguishing normal aging, MCI and AD [23,81,83,84]

\section{Alpha waves and cognition}

Alpha waves (frequency $8-12 \mathrm{~Hz}$ and amplitude $10-150 \mu \mathrm{V}$ ) discovered in 1924 by Hans Berger are electrical waves emitted by the cerebral cortex of the brain [99]. There are several theories on the generators of alpha waves (Figure 4): a) thalamus model, b) cortical generator model, c) thalamo-cortical model and d) thalamic neural mass model [100-103]. Figure 1a and Figure 1c show the pertinent Alpha wave form recorded using NeuralScan by Medeia NeuralScan has inbuilt software to carry out routine clinical assessment of EEG wave forms (alpha, beta, theta or gamma) both for research and clinical purposes

Earlier studies on their predominance and origination led to the hypothesis of "cortical idling" [104]. The theory (Figure 4) attributes alpha wave origination to the occipital lobe/areas of the cerebral cortex not in use/idle and fronto-central cerebral cortex during semiarousal period (inverse of rapid eye movement-REM sleep). Studies on their predominance showed increased alpha waves (event-related synchronization or ERS): during eyes closed in wakeful relaxation but not sleepy state and when a person is on auto-pilot/prior-to-a-mistake/ idle/not-paying attention with reduced alpha waves (event-related desynchronization or ERD) with eyes open, drowsiness and sleep.

However work in the area of cognition showed the converse, that alpha ERS also occurs during competing tasks and focused attention and had an important functional role in cognition. Here, in order to "carry out a task"/"focus ones attention", one had to block/suppress/ inhibit certain task-irrelevant cortical regions and unblock/express/ release from inhibition the task-relevant regions of the cortex; the inhibition-timing hypothesis (Figure 4) [105]. In such instances alpha ERS was seen in task-irrelevant cortical regions with alpha ERD in taskrelevant regions of the cortex. Most studies have been conducted in areas where top-down (cognitive) versus bottom-up control was evaluated in response to an event. These characteristics have been investigated over the years to identify their role in brain and mental health and disease states. The present work focuses on the a) role of alpha waves in cognition, and b) cognitive impairments seen in: i) normal aging, ii) presenile and senile dementia of the Alzheimer's type (SDAT).

Alpha-oscillation-influenced-cortical-functionality is today known to influence the somatosensory, visual and auditory system and cognition based on the inhibition-timing hypothesis $[105,106]$.

Haegens trained a monkey (Pavlov-Operant learning/memory) to identify if the second vibrotactactile stimuli (f2) to the right fingers (500-ms pulse trains with frequencies of 10-34 Hz. lasting $20 \mathrm{~ms}$.) presented after a 3-s retention period was of lower or higher frequency than the first (f1) by pressing a button following a 3-s forced delay with a reward in terms of a drop of liquid $[107,108]$. Local field potentials (LFPs) and spikes from primary somatosensory cortex (S1), secondary somatosensory cortex (S2), dorsal premotor cortex (DPC), medial premotor cortex (MPC), and primary motor cortex (M1) were recorded. Alpha ERD was observed during somatosensory discrimination, stimulus presentation and, in premotor and motor regions, during the decision delay, but the decrease was less pronounced in sensory regions and overall it was inversely correlated with better task performance.

The study also illustrated that alpha oscillations played an important top-down functional role in both sensory and motor processes

Table 3. ERP and Alpha waves in Cognitive Impairments like AD

\begin{tabular}{|c|c|c|}
\hline Role & Particulars & References \\
\hline Normal aging & $\begin{array}{l}\text { Abnormally low }(<8 \mathrm{~Hz}) \text { alpha waves with temporal intermittent polymorphic slowing that was lateralized to the left } \\
\text { side without focal neurological or neuropsychological abnormalities. Increased fast activity, diffuse slowing, and } \\
\text { focal disturbances }\end{array}$ & {$[115,116]$} \\
\hline \multirow{2}{*}{$\begin{array}{l}\text { Healthy Controls }(\mathrm{HC}) \text { versus } \\
\text { MCI }\end{array}$} & $\begin{array}{l}\text { Increasing alpha power, enhanced alpha coherence, objective and working memory disturbances distinguish cortical } \\
\text { processing of MCI and controls during memory activities. }\end{array}$ & {$[114,118,119]$} \\
\hline & $\begin{array}{l}\text { Theta/Alpha Ratio study younger adults differentially recruited disparate neural regions and frequency bands than } \\
\text { older adults with MCI in response to task engagement. higher theta power with relative decrease in alpha power in } \\
\text { the study phase in medial/temporal channels by older adults }\end{array}$ & {$[120]$} \\
\hline $\begin{array}{l}\mathrm{HC}, \mathrm{MCI} \text { without } \mathrm{DM}, \mathrm{MCI} \\
\text { with } \mathrm{DM}\end{array}$ & $\begin{array}{l}\text { Peak power frequency of alpha } 2 \text { is higher, with significantly higher hippocampal atrophy and alpha-2/alpha- } 1 \text { power } \\
\text { ratio among MCI with DM, than MCI without DM and HC groups }\end{array}$ & [128] \\
\hline $\begin{array}{l}\text { Differentiating frontotemporal } \\
\text { dementia (FTD) from } \\
\text { Alzheimer's disease (AD) }\end{array}$ & $\begin{array}{l}\mathrm{HC} \alpha \text {-generators are in the posterior regions of the brain. } \\
\text { In AD compared to } \mathrm{HC}, \delta \text { power increase, with } \alpha 1, \alpha 2, \beta 1 \text { and } \beta 2 \text { power decrease producing a shift to more anterior } \\
\text { regions i,e, "anteriorization" of } \alpha \text {-rhythm. } \\
\text { FTD patients compared to HC decrease of } \delta \text { power and higher } \alpha 2 \text { and } \beta 1 \text { values over the posterior regions. }\end{array}$ & [129] \\
\hline $\begin{array}{l}\text { Memory and Attention } \\
\text { modulation }\end{array}$ & $\begin{array}{l}\text { Alpha waves play a crucial role in sensory gating aiding in focused attention via attention modulation. They block or } \\
\text { prevent intrusion of irrelevant memories/tasks and promote via a release from inhibition of relevant tasks/memories. } \\
\text { Individuals with MCI and AD have problems in focused attention and memory when alteration or changes occur in } \\
\text { this balance. }\end{array}$ & [130-132] \\
\hline
\end{tabular}



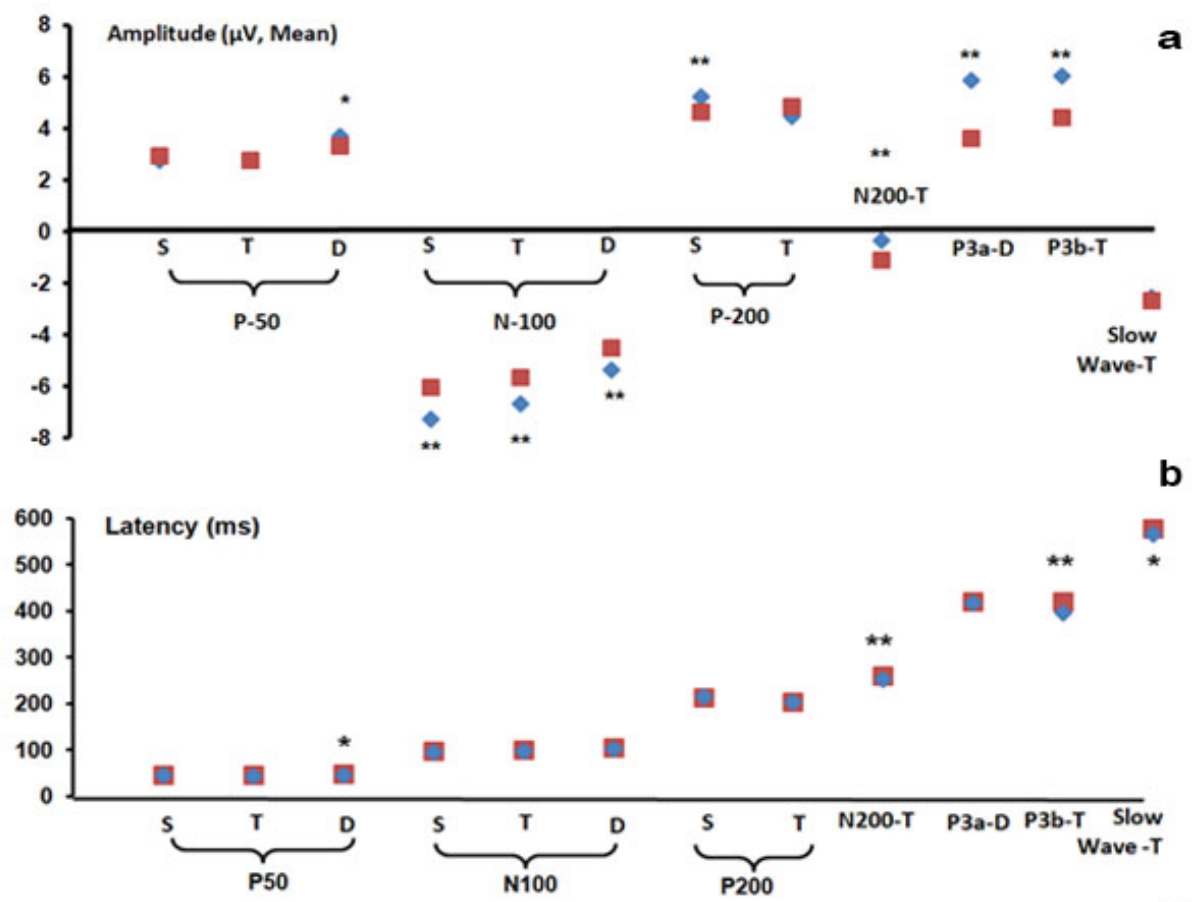

b

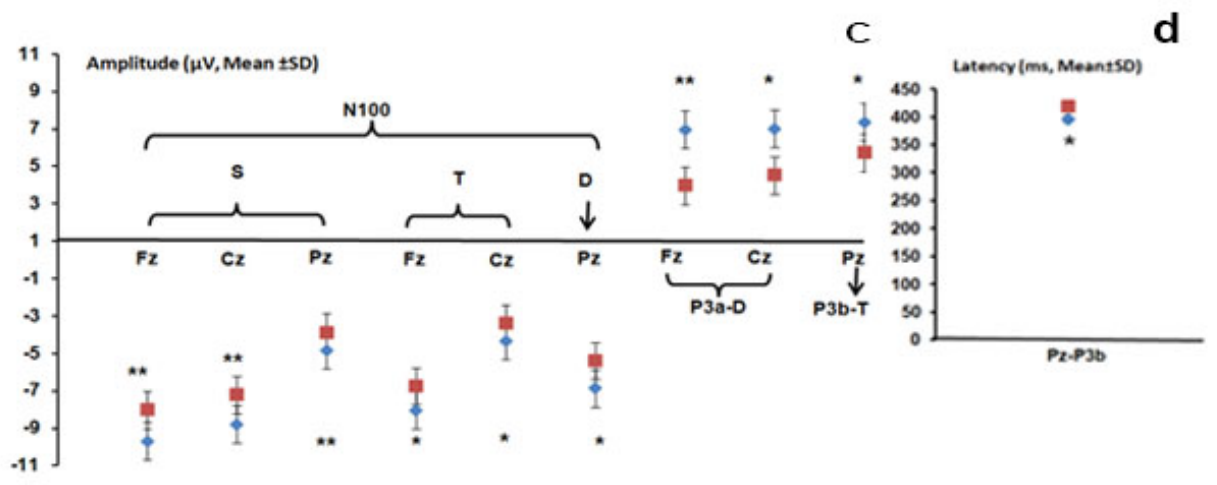

HC: Healthy Controls, AD: Mild Alzheimer's disease; D: Distracter, S: Standard;T: target;

${ }^{* *} \mathrm{p}<0.005 ;{ }^{*} \mathrm{p}<0.05 \leftrightarrow \mathrm{HC}=\mathrm{AD}$

Cecchi $M$ et al. Alzheimers Dement (Amst). 2015 Oct 2;1(4):387-94

Figure 2. ERP component features a) Amplitude $(\mu \mathrm{V})$, b) Latency $(\mathrm{ms})$ and follow-up single-channel analysis of statistically significant ERP components at single midline electrodes (Fz, $\mathrm{Cz}$, and Pz;10/20 system): c) P3a, N100, P3b (Amplitude, $\mu \mathrm{V}$ ) and d) P3b (Latency, ms) in HC and mild AD

$[107,108]$. The question of how alpha wave oscillations influenced cognitive aspects at the physiological level was illustrated by alpha ERD resulting in cell firing (action potential, AP). The pulsed phasic and inhibitory aspect of alpha ERS was highlighted at baseline and during retention especially in the motor and pre-motor regions. Here a direct relationship was observed, as stronger the ERS, stronger was the inhibition. Studies on monkeys presented with either a visual or auditory stimulus also showed ERS increased auditory stimulus detection in V2 and V4 with ERD in V1. Further V1, V2 and V4 coherence decreased with decreased visual attention. In the inferotemporal cortex (IT, involved in visual processing), alpha ERD resulted in faster auditory detection while prestimulus alpha ERS increased with visual attention and resulted in increase in AP firing at the physiological level [107-109].

In a study on 18 healthy human subjects aged 25-33 years (female\%: $61.1 \%$ ); a visuoelectrical stimulus was presented to either the left or the right hand [110]. Subjects were cued by an arrow to indicate which hand was going to be stimulated. They were also made familiar to what a low frequency and high frequency stimuli was like. After a prestimulus of 1.4 -s an electrical stimulus ( $240 \mathrm{~ms}$ pulse train) was presented to the cued had immediately following presenting a "distracter" stimulus (one pulse) to the non-cued hand, while the subject was instructed to keep their eyes fixated on a fixation cross. If the subject felt that the electrical stimulus was of a lower frequency they were required to press the lower button and if it was of a higher frequency the upper button.

Findings were; top-down alpha activity was seen and alpha power at prestimulus in the primary sensorimotor regions was strongly lateralized [110]. Alpha power increased with accuracy and speed of the response and as the subjects became familiar with the cue and their power of discrimination increased. While lateralization was directed by alpha ERD at prestimulus contralateral to the cued side, it was driven by slight ipsilateral ERS if the cue was presented to the right hand. Both ipsi- and contralateral cueing was followed by alpha ERD over the left 


\section{ERP components a) Amplitude and b) Latency in Controls versus $\mathrm{MCI}$}

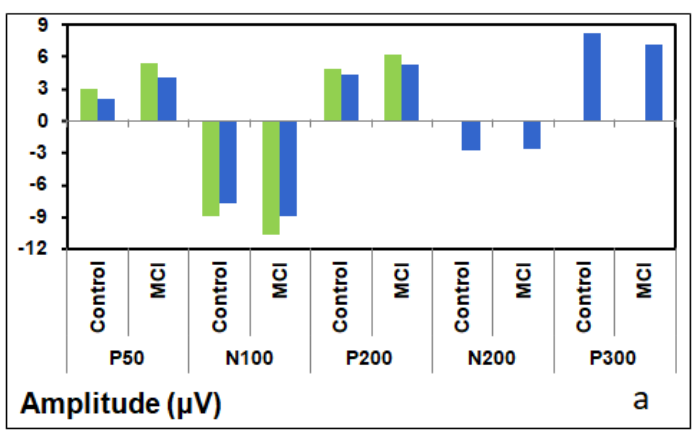

Golob EJ et al. Clin Neurophysiol. 2001 Jan;113(1):151-61

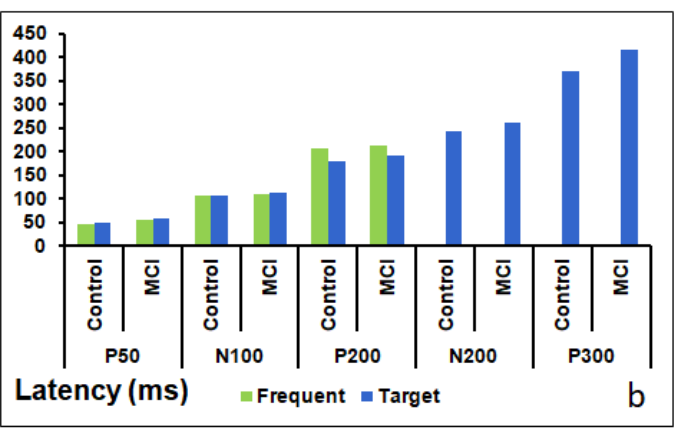

\section{ERP component: $\mathrm{c}$ ) Diagnostic value of P50 in $\mathrm{MCl}-\mathrm{AD}$ and $\mathrm{MCl}$-other at $\mathrm{C} 3$ and $\mathrm{Cz}$ elicited by standard, target and novel stimuli}

Green DL et al. Brain Res. 2015 Oct 22;1624:390-397

\begin{tabular}{|l|l|c|c|c|c|c|c|c|}
\hline \multirow{2}{*}{$\begin{array}{c}\text { EEG } \\
\text { Electrode }\end{array}$} & \multirow{2}{*}{ Stimuli } & \multicolumn{2}{c|}{ Mean Amplitude $(\mu \mathrm{V})$} & \multicolumn{2}{c|}{ OR (Odds Ratio) } & \multicolumn{3}{c|}{ Diagnostic Value } \\
\cline { 3 - 9 } & & MCl-AD & MCl-other & P50 at C3 \& Cz & Education & Sen. & Spec. & Accuracy \\
\hline \multirow{2}{*}{ C3 } & Standard & 1.35 & -0.08 & $8.745^{\star \star}$ & $1.757^{\star \star}$ & 94.7 & 94.1 & 94.4 \\
\cline { 2 - 9 } & Target & 0.87 & -0.18 & N/A & N/A & N/A & N/A & N/A \\
\cline { 2 - 9 } & Novel & 1.92 & 0.89 & N/A & N/A & N/A & N/A & N/A \\
\hline \multirow{3}{*}{ Cz } & Standard & 1.02 & -0.08 & $7.006^{\star \star}$ & $1.485^{\star \star}$ & 84.2 & 88.2 & 86.1 \\
\cline { 2 - 9 } & Target & 0.77 & -0.31 & 2.256 & $1.331^{\star}$ & 78.9 & 76.5 & 77.8 \\
\cline { 2 - 9 } & Novel & 1.5 & 0.6 & 1.933 & $1.384^{\star}$ & 78.9 & 82.4 & 80.6 \\
\hline
\end{tabular}

Education (Median (range) years: $\mathrm{MCl}-\mathrm{AD} 16(11-20)$ and $\mathrm{MCl}-$ other 12 (4-18))

Sen.: sensitivity; Spec.: Specificity, ${ }^{* *} \mathrm{p}<0.005,{ }^{*} \mathrm{p}<0.05$

Figure 3. Results of Two studies on the role of ERP component P50, N100, P200, N200, P300 a) Amplitude ( $\mu$ V), b) Latency (ms) and c) P50 Diagnostic value

sensorimotor cortex which marked preparation for the motor response. Better ERS over the ipsilateral somatosensory regions resulted in better somatosensory WM performance [110]. In a cued spatial attention study where subjects were cued to either direction their attention to their hand or foot alpha accordingly ERS was observed in the respective areas where attention was paid [111].

If one considers the working brain as a network of regions with information being routed to task-relevant regions and blocked/gated via inhibition in task-irrelevant regions [112]. Then as alpha activity is the strongest signal recorded by EEG it is therefore probable that information routing in task-relevant regions via alpha ERD and inhibition in task-irrelevant via alpha ERS could be a key player. Further, alpha activity in task-irrelevant areas could be used as a surrogate marker of optimal task performance in a task-relevant region [112].

\section{Alpha waves and Cognitive impairments in normal aging and dementia}

Studies using EEG signals and neuroimaging have correlated their activity and the parietal lobes with different kinds of cognitive information processing (memory, language, concept retrieval and music processing) [113,114]. Table The lateral prefrontal cortex, mediotemporal areas, posterior association cortex, temporal lobe, hippocampus, and parietal lobe are functionally involved with memory in general and working memory, which is responsible for information encoding, maintenance and decoding [114]. Thus age related changes in these areas would result in changes in brain wave oscillations and coherence [114]. In terms of EEG changes aging was earlier characterized by slowing of the alpha rhythm, increased fast activity, diffuse slowing, and focal disturbances [115] Increasing alpha power, enhanced alpha coherence, objective and working memory disturbances distinguish cortical processing of MCI and controls during memory activities.

In a study of 12 cognitively and physically healthy participants (age: mean 94 years, range: 91-99 years; females\% 66.7\%, and MMSE mean score 29; range: 26-30) from the 90+ Study; 10 out of the 12 had abnormal EEG rhythms, background alpha rhythms were found to be abnormally low $(<8 \mathrm{~Hz})$ with temporal intermittent polymorphic slowing that was lateralized to the left side without focal neurological or neuropsychological abnormalities [116]. Temporal slowing is attributed to deep cerebral white matter hyperintensities in $>84$ year old subjects [117].

In three studies $(n=69)$ that compared EEG coherence and working memory (WM) in subjects with mild cognitive impairments $(\mathrm{n}=35$, age range $=52 \sim 71$ years) and healthy controls ( $\mathrm{HC} ; \mathrm{n}=34$, female $\%: 50 \%$, age range $=51 \sim 63$ years) inter- and intra-hemispheric coherence with eyes closed for alpha-1 $(8.0 \sim 10.0 \mathrm{~Hz})$, alpha-2 $(10.5 \sim 13.0 \mathrm{~Hz})$ was examined [21, 25-26]. Inter-hemispheric coherence of F3-F4, C3-C4, P3-P4, T5T6 and O1-O2 electrode pairs and intra-hemispheric coherence of F3C3, F4-C4, C3-P3, C4-P4, P3-O1, P4-O2, T5-C3, T6-C4, T5-P3 and T6$\mathrm{P} 4$ electrode pairs were evaluated $[117,118,119]$. The inter-hemispheric coherence values in MCI patients were significantly higher than that in controls during all three working memory levels and especially so in the left-right centrals (C3-C4) and left-right parietal (P3-P4). $\mathrm{HC}$ and MCI groups did not differ $(\mathrm{p}>0.05)$ by Mini-mental state examination (MMSE) and resting inter- and intra-hemispheric EEG coherence between two groups at rest. However, the MCI group was significantly higher $(\mathrm{p}<0.05)$ than $\mathrm{HC}$ in inter- and intra-hemispheric 


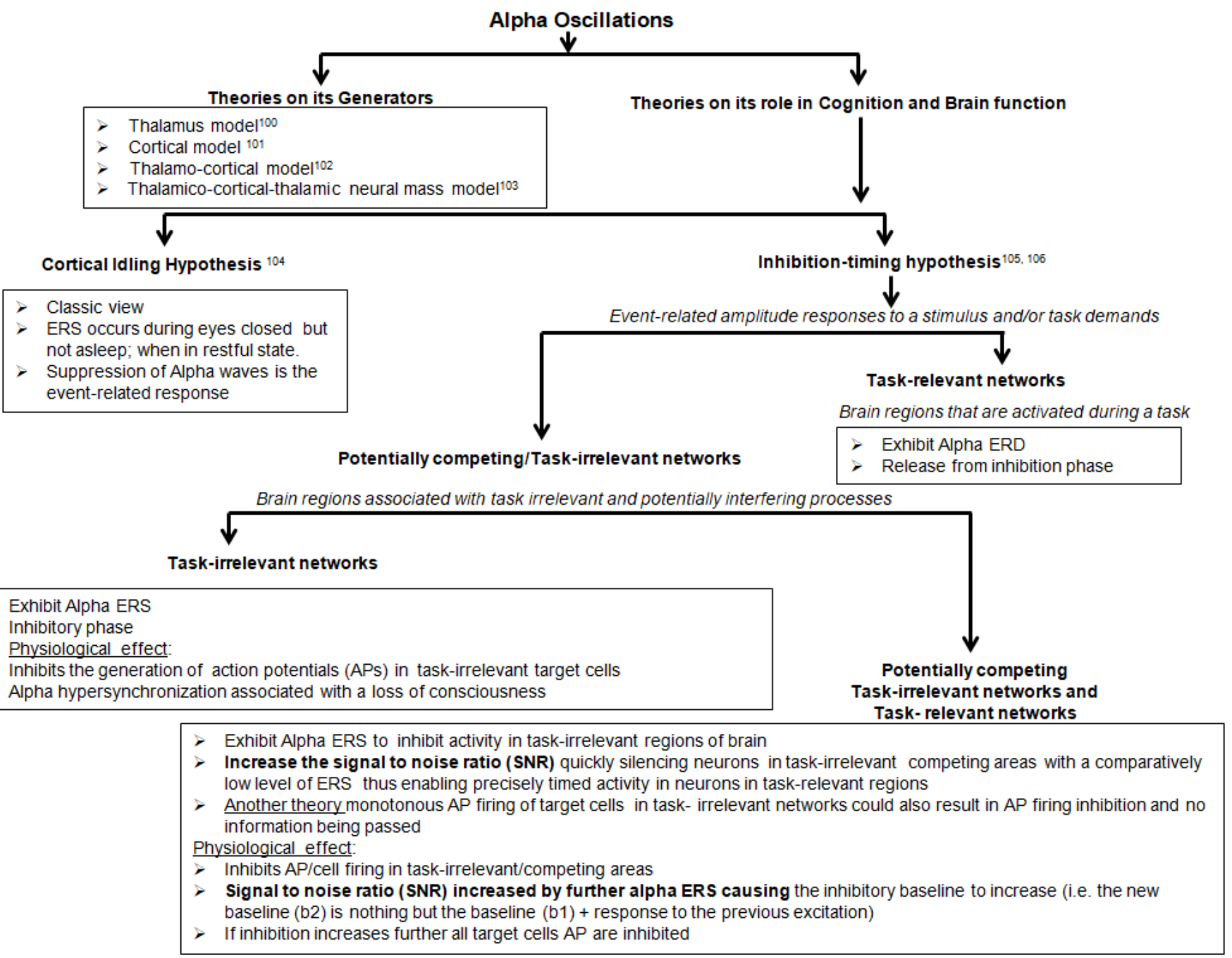

Figure 4. Theories on role of Alpha oscillations in cognition and brain function

Event-Related synchronization (ERS): Increase in alpha amplitude/power;

Event-Related desynchronization (ERD): Decrease in alpha amplitude/power

EEG coherence for working memory tasks. The finding was attributed to MCI subjects having developed a higher degree of inter- and intrahemispheric functional connectivity during working memory task as a compensatory mechanism for failure of normal cortical connections in order to maintain processing effectiveness however processing efficiency was reduced. Further coherence values fell at WM1 below resting condition (i.e. alpha ERD occurred) and then rose higher and higher for WM2 and WM3 (i.e. alpha ERS occurred) serving to illustrate that working memory tasks too exhibited the "focal ERD/ surround ERS" phenomenon.

A Theta/Alpha Ratio study showed that younger adults differentially recruited disparate neural regions and frequency bands than older adults in response to task engagement. Greater prestimulus interval alpha power was found in the occipitotemporal areas followed by higher theta power with relative decrease in alpha power in the study phase in medial/temporal channels by older adults. They also showed a showed a task-related decrease in alpha in the lateral parietal cortex, lateral prefrontal cortex (PFC), and lateral temporal regions particularly on the left (all studies were on right- handed individuals) which could be attributed to alterations in blood circulation and metabolism. Younger adults showed greater relative beta power during the post-stimulus period compared to the prestimulus period [120].

EEG and QEEG studies have shown that individuals with diabetes $(\mathrm{DM})$ are at an increased risk for developing dementia [121]. Peak power frequency of alpha 2 (alpha-1:8 to $<11.0 \mathrm{~Hz}$, alpha-2:11 to < $14 \mathrm{~Hz})$ is higher, with significantly higher hippocampal atrophy (6 (37.5\%), $2(12.5 \%), 0(0.0 \%), \mathrm{p}<0.05)$ and alpha-2/alpha- 1 power ratio among MCI with DM, than MCI without DM and HC groups [122]. Increase in the alpha power (alpha 2) could be due to hyperpolarization at thalamic level [122].

EEG studies have also been used to differentiate between frontotemporal dementia (FTD) and Alzheimer's disease (AD) both of which have clinically overlapping symptoms [123]. In normal subjects (HC), $\alpha$ generators are in the posterior regions of the brain. In $\mathrm{AD}$ patients compared to $\mathrm{HC}$, showed a significant $\delta$ occipital power increase with significant parietooccipital $\alpha 1$ and temporal $\alpha 2$ power decrease and widespread $\beta 1$ and $\beta 2$ power decrease with a decrease 
of posterior a activity producing a shift to more anterior regions I,e, "anteriorization" of $\boldsymbol{\alpha}$-rhythm. FTD patients compared to HC showed a decrease of $\delta$ power and higher $\alpha 2$ and $\beta 1$ values over the posterior regions.

This disparate neural recruitment, compensatory mechanisms (illustrated by increased hemispheric coherence) due to nonselective recruitment/dedifferentiation, combined with alpha modulations linked to top-down attention and sensory gating [105,106], even when hippocampal volumes were preserved in could be a reason why older adults require more effort to filter out distracting information while slower response times, could be due to a deficit in speed of processing deficit [120-122].

\section{Therapies aimed at improving alpha oscillations}

In terms of therapies aimed at improving alpha oscillations studies have shown that cholinergic neuromodulation either drug-induced or by induction of large alpha power via neurofeedback training or repetitive transcranial magnetic stimulation (rTMS) or via the technique of using flashing lights, with parallel sound, in a binaural beats activation version resulted in improvement in the top-down impact of spatial attention on alpha oscillations in the human visual cortex [123,124].

Thalamocortical interactions modulate a-rhythms which in turn modulate the transmission of sensorimotor and cognitive information among subcortical and cortical pathways. The cholinergic theory proposed that a significant decrease in the presynaptic cholinergic material in cortical synapses with cognitive dysfunction in normal elderly people and patients with AD. Significant reduction in coherence is associated with increased genetic susceptibility of ApoE and derangements in the transfer of cholinergic neurotransmitter [123,124]. Cholinergic neurons i.e acetylcholinesterase (AChE)-positive neurons modulate cortical processing and responses to new and relevant stimuli. Butyrylcholinesterase (BuChE)-positive neurons play a role in attention [125-127]. AChE and BuChE in thalamic nuclei project diffusely to the cortex and frontal cortex respectively. Cholinergic stimulation results in a shift towards faster frequencies, whereas interference with cholinergic function or a hypofunctional cholinergic system leads to an increase in slow wave activity [127]. Treatment with cholinesterase inhibitors helps inhibit acetyl and/or butyryl cholinesterases that are responsible for the breakdown of acetylcholine in the brain [125-127]. The power increase of alpha spectral power correlated with the modulation of butyrylcholinesterase on thalamic nuclei restoring of the cholinergic system to near physiological levels resulted in the improvement of cognitive performance [128-130].

In terms of Alpha wave entrainment, in a study of 75 individuals: elderly without dementia diagnosis $(n=15)$ (EWD), elderly diagnosed with Parkinson's disease (EDP) $(n=15)$, elderly diagnosed with Alzheimer's disease (EDA) $(n=15)$, children with normal cognitive development (CND) $(n=10)$, children with autism (CA) $(n=10)$, and children with intellectual impairment $(\mathrm{CII})(\mathrm{n}=10)$. Brain stimulation by light and binaural beats was carried out for 15 minutes, i.e. at 0 -to3 -minute waves were induced at $8 \mathrm{~Hz}$, at 4 -to- 6 - minute waves at $10 \mathrm{~Hz}$, the 7-to-9-minute waves at $12 \mathrm{~Hz}$, the 10 -to- 12 -minute waves at $14 \mathrm{~Hz}$, and the 13-to-15-minute waves at $15 \mathrm{~Hz}$ were induced. Improvements in word recognition and working memory were seen. The CA group i.e. autistic individuals, who had significantly lower brain excitability compared to $\mathrm{HC}$ in the beginning showed an increase in brain excitability which though temporary in the present study is indicative of the possibility of neuroplastic changes [124].
These findings have enormous implications not only for individuals with $\mathrm{AD}$ and Parkinson's but also in diseases/disorders which could benefit by improving motor functions namely; poststroke situations, temporal lobe activation of autistic children, attention concentration improvement of children diagnosed as low learners, working memory and attentional deficits of hyperactive children, and for children kinesthetic sense improvement [123,124].

\section{Conclusion}

Aging gracefully and prevention and control of dementia and Alzheimer's will be possible only if research, discovery, industry and therapy work seamlessly to ensure the bridging of gaps and quick translation of research. A better understanding of neuron chatter/ firing via EEG and an integrated approach in neurocognitive research, development and therapy is a step in the right direction. NeuralScan by Medeia is one such example of a clinician friendly EEG machine, that was developed for the clinician guided by their feedback, which also features the latest technology both from the standpoint of industry and research. Knowing the role and features of Alpha waves and ERP components in normal cognition and their change in features during cognitive impairments seen in aging, $\mathrm{MCI}$ and $\mathrm{AD}$ is imperative when planning and designing better and more appropriate diagnosis, management and treatment modalities.

\section{References}

1. National Institute on Aging (2011) Global health and aging - world health organization national institute on health \#11-7737.

2. World Health Organization (2015) The epidemiology and impact of dementia.

3. Alzheimer's Disease International (2013) Policy brief for g8 heads of government. the global impact of dementia 2013-2050. london: alzheimer's disease international.

4. World Health Organization (2012) Dementia: A public health priority. Geneva: World Health Organization

5. Duthey B (2013) Alzheimer's disease - world health organization

6. GBD (2016) Dementia collaborators. global, regional, and national burden of alzheimer's disease and other dementias, 1990-2016: a systematic analysis for the global burden of disease study. Lancet Neurol 18: 88-106.

7. Lo RY (2017) The borderland between normal aging and dementia. Ci Ji Yi Xue Za Zhi 29: 65-71. [Crossref]

8. Jagust W (2013) Vulnerable neural systems and the borderland of brain aging and neurodegeneration. Neuron 77: 219-234.

9. Mayeux R, Stern Y (2012) Epidemiology of alzheimer disease. Cold Spring Harb Perspect Med 2. [Crossref]

10. American Psychiatric Association (2013) Diagnostic and statistical manual of mental disorders (5th ed.). Arlington, VA: American Psychiatric Association.

11. Folstein MF, Folstein SE, McHugh PR (1975) Mini mental state": a practical method for grading the cognitive state of patients for clinician. J Psychiatr Res 12: 189-198.

12. Kalafat M, Hugonot-Diener L, Poitrenaud J (2013) The mini mental state (MMS): French standardization and normative data. Rev. Neuropsychol 13: 209-236.

13. Nasreddine ZS, Phillips NA, Bedirian V, Charbonneau S, Whitehead V, et al. (2005) The Montreal Cognitive Assessment, MoCA: a brief screening tool for mild cognitive impairment. J Am Geriatr Soc 53: 695-699

14. Hughes CP, Berg L, Danziger WL, Coben LA, Martin RL (1982) A new clinical scale for the staging of dementia. Br J Psychiatry 140: 566-572. [Crossref]

15. Rosen WG, Terry RD, Fuld PA, Katzman R, Peck A (1980) Pathological verification of ischemic score in differentiation of dementias. Ann Neurol 7: 486-488. [Crossref]

16. Lawton MP, Brody EM (1969) Assessment of older people: self-maintaining and instrumental activities of daily living. Gerontologist 9: 179-186. [Crossref]

17. Blennow K, Dubois B, Fagan AM, Lewczuk P, de Leon MJ, et al. (2015) Clinica utility of cerebrospinal fluid biomarkers in the diagnosis of early Alzheimer's disease. Alzheimers Dement 11: 58-69. 
18. Blennow K, Vanmechelen E, Hampel H (2001) CSF total tau, Abeta42 and phosphorylated tau protein as biomarkers for Alzheimer's disease. Mol Neurobiol 24: 87-97. [Crossref]

19. Hertze J, Minthon L, Zetterberg H, Vanmechelen E, Blennow K, et al. (2010) Evaluation of CSF biomarkers as predictors of Alzheimer's disease: a clinical follow-up study of 4.7 years. J Alzheimers Dis 21: 1119-1128. [Crossref]

20. Blennow K, Hampel H, Weiner M, Zetterberg H (2010) Cerebrospinal fluid and plasma biomarkers in Alzheimer disease. Nat Rev Neurol 6: 131-144.

21. Blennow K, Hampel H (2003) CSF markers for incipient Alzheimer's disease. Lancet Neurol 2: 605-613. [Crossref]

22. Blennow K, Zetterberg H, Fagan AM (2012) Fluid biomarkers in alzheimer disease. Cold Spring Harb Perspect Med 2: a006221. [Crossref]

23. Sucholeiki R. Normal EEG Waveforms. Available from https://emedicine.medscape. com/article/1139332-overview

24. Thatcher RW, Lubar JF (2008) History of the scientific standards of qeeg normative databases. published in: "introduction to qeeg and neurofeedback: advanced theory and applications" Eds: Budzinsky T, Budzinski H, Evans J, Abarbanel A. Academic Press, San Diego, CA, 2008.

25. Pascual-Marqui RD, Lehmann D, Koukkou M, Kochi K, Anderer P, et al. (2011) Assessing interactions in the brain with exact low-resolution electromagnetic tomography. Philos Trans A Math Phys Eng Sci 369: 3768-3784.

26. Coles MGH, Rugg MD (2008) Event-related brain potentials: An introduction. In M. D. Rugg \& M. G. H. Coles (Eds.), Electrophysiology of mind: Event-related brain potentials and cognition. 1995: 1-26. Oxford, UK: Oxford University Press. Coles, M. G.

27. Herrmann CS, Knight RT (2001) Mechanisms of human attention: Event-related potentials and oscillations. Neuroscience \& Biobehavioral Reviews 25: 465-476.

28. Hillyard SA, Anllo-Vento L (1998) Event-related brain potentials in the study of visual selective attention. Proceedings of the national academy of sciences of the united states of america 95: 781-787.

29. Näätänen R, Michie PT (1979) Early selective-attention effects on the evoked potential: A critical review and reinterpretation. Biological Psychology 8: 81-136.

30. Luck SJ, Heinze HJ, Mangun GR, Hillyard SA (1990) Visual event-related potentials index focused attention within bilateral stimulus arrays. II. Functional dissociation of P1 and N1 components. Electroencephalography and Clinical Neurophysiology 75: 528-542.

31. Heinze HJ, Mangun GR, Burchert W, Hinrichs H, Scholz M, et al. (1994) Combined spatial and temporal imaging of brain activity during visual selective attention in humans. Nature 372: 543-546.

32. Gomez-Gonzales CM, Clark VP, Fan S, Luck SJ, Hillyard SA (1994) Sources of attention-sensitive visual event-related potentials. Brain Topography 7: 41-51

33. Yamazaki T, Kamijo KI, Kenmochi A, Fukuzumi SI, Kiyuna T, et al. (2000) Multiple equivalent current dipole source localization of visual event related potentials during oddball paradigm with motor response. Brain Topography 12: 159-175.

34. Clark VP, Fan S, Hillyard SA (1994) Identification of early visual evoked potential generators by retinotopic and topographic analyses. Human Brain Mapping 2: 170-187.

35. Novak G, Ritter W, Vaughan HG (1292) Mismatch detection and the latency of temporal judgments. Psychophysiology 29: 398-411.

36. García-Larrea L, Lukaszewicz AC, Mauguiére F (1992) Revisiting the oddball paradigm. Non-target vs neutral stimuli and the evaluation of ERP attentional effects. Neuropsychologia 30: 723-741.

37. Conley EM, Michalewski HJ, Starr A (1999) The N100 auditory cortical evoked potential indexes scanning of auditory short-term memory. Clinical Neurophysiology 110: 2086-2093.

38. Potts GF, Patel SH, Azzam PN (2004) Impact of instructed relevance on the visual ERP. International Journal Psychophysiology 52: 197-209.

39. Potts GF, Dien J, Harty-Speiser AL, McDougal LM, Tucker DM (1998) Dense sensor array topography of the event-related potential to task-relevant auditory stimuli. Electroencephalography and Clinical Neurophysiology 106: 444-456.

40. Potts GF, Liotti M, Tucker DM, Posner MI (1996) Frontal and inferior temporal cortical activity in visual target detection: Evidence from high spatially sampled event-related potentials. Brain Topography 9: 3-14.
41. Kenemans JL, Kok A, Smulders FTY (1993) Event related potentials to conjunctions of spatial frequency and orientation as a function of stimulus parameters and response requirements. Electroencephalography and Clinical Neurophysiology 88: 51-63.

42. Näätänen R, Gaillard AWK, Mäntysalo S (1978) Early selective-attention effect on evoked potential reinterpreted. Acta Psychologica 42: 313-329.

43. Näätänen R, Schröger E, Karakas S, Tervaniemi M, Paavilainen P (1993) Development of a memory trace for a complex sound in the human brain. NeuroReport 4: 503-506.

44. West R (2003) Neural correlates of cognitive control and conflict detection in the Stroop and digit-location tasks. Neuropsychologia 41: 1122-1135.

45. West R, Bowry R, McConville C (2004) Sensitivity of medial frontal cortex to response and nonresponse conflict. Psychophysiology 41: 739-748.

46. Donkers FCL, van Boxtel GJM (2004) The N2 in go/no go tasks reflects conflict monitoring not response inhibition. Brain and Cognition 56: 165-176.

47. Polich J (2003) Theoretical overview of P3a and P3b. In J. Polich (Ed.), Detection of change: Event-related potential and fMRI findings.Boston, MA: Kluwer Academic Press.

48. Pritchard WS (1981) Psychophysiology of P300. Psychol Bull 89: 506-540. [Crossref]

49. Katayama J, Polich J (1998) Stimulus context determines P3a and P3b. Psychophysiology 35: 23-33.

50. Friedman D, Simpson GV, Hamberger M (1993) Age related changes in scalp topography to novel and target stimuli. Psychophysiology 30: 383-396.

51. Knight RT (1984) Decreased response to novel stimuli after prefrontal lesions in man Electroencephalography and Clinical Neurophysiology 59: 9-20.

52. Knight RT (1996) Contribution of human hippocampal region to novelty detection. Nature 383: 256-259.

53. Baudena P, Halgen E, Heit G, Clarke JM (1995) Intracerebral potentials to rare target and distractor auditory and visual stimuli. III. Frontal cortex. Electroencephalography and Clinical Neurophysiology 94: 251-264.

54. Elting JW, Maurits N, van Weerden T, Spikman J, De Keyser J, et al. (2008) P300 analysis techniques in cognitive impairment after brain injury: Comparison with neurophsychological and imaging data. Brain Injury 22: 870-81.

55. Dien J, Spencer KM, Donchin E (2003) Localization of the event-related potential novelty response as defined by principal components analysis. Cognitive Brain Research 13: 637-650.

56. Goto Y, Brigell MG, Parmeggiani L (1996) Dipole-modeling of the visual evoked P300. J Psychosom Res 41: 71-79. [Crossref]

57. Mecklinger A, Maess B, Opitz B, Pfeifer E, Cheyne D (1998) A MEG analysis of the P300 in visual discrimination tasks. Electroencephalography and Clinical Neurophysiology 108: 45-66.

58. Rogers RL, Basile LFH, Papanicolaou AC, Eisenberg HM (1993) Magnetoencephalography reveals two distinct sources associated with late positive evoked potentials during visual oddball task. Cerebral Cortex 3: 163-169.

59. Halgren E, Marinkovic K, Chauvel P (1998) Generators of the late cognitive potentials in auditory and visual oddball tasks. Electroencephalography and Clinical Neurophysiology 106: 156-164.

60. Knight RT (1997) Distributed cortical network for visual attention. Journal of Cognitive Neuroscience. 9: 75-91.

61. Townsend J, Westerfield M, Leaver E, Makeig S, Jung TP, et al. (2001) Event-related brain response abnormalities in autism: Evidence for impaired cerebello-frontal spatial attention networks. Cognitive Brain Research 11: 127-145.

62. Falkenstein M, Hoormann J, Christ S, Hohnsbein J (2000) ERP components on reaction errors and their functional significance: A tutorial. Biological Psychology 51: 87-107.

63. Overbeek TJM, Nieuwenhuis ST, Ridderinkhof KR (2005) Dissociable components of error processing. Journal of Psychophysiology 19: 319-329.

64. Nieuwenhuis S, Ridderinkhof KR, Blom J, Band GPH, Kok A (2001) Error-related brain potentials are differentially related to awareness of response errors: Evidence from an antisaccade task. Psychophysiology 38: 752-760.

65. van Veen V, Carter CS (2002) The timing of action monitoring processes in the anterior cingulate cortex. Journal of Cognitive Neuroscience 14: 593-602.

66. Bush G, Luu P, Posner MI (2000) Cognitive and emotional influences in anterior cingulate cortex. Trends in Cognitive Sciences 4: 215-222. 
67. Gehring WJ, Knight RT (2000) Prefrontal-cingulate interactions in action monitoring. Nature Neuroscience 3: 516-520

68. Herrmann MJ, Römmler J, Ehlis AC, Heidrich A, Fallgatter AJ (2004) Source localization (LORETA) of the error-related-negativity (ERN/Ne) and positivity (Pe). Cognitive Brain Research 20: 294-299.

69. Gehring WJ, Goss B, Coles MGH, Meyer DE, Donchin E (1993) A neural system for error detection and compensation. Psychological Science 4: 385-390.

70. Luu P, Tucker DM, Derryberry D, Reed M, Poulsen C (2003) Electrophysiological responses to errors and feedback in the process of action regulation. Psychological Science 14: 47-53.

71. Ridderinkhof KR, Ullsperger M, Crone EA, Nieuwenhuis S (2004) The role of the medial frontal cortex in cognitive control. Science 306: 443-447.

72. Korzyukov O, Pflieger ME, Wagner M, Bowyer SM, Rosburg T, et al. (2007) Generators of the intracranial P50 response in auditory sensory gating. Neuroimage 35: 814-826.

73. Picton T, Hillyard S, Krausz H, Galambos R (1974) Human auditory evoked potentials: I. Evaluation of components. Electroencephalography \& Clinical Neurophysiology 36: 179-190.

74. Irimajiri R, Golob EJ, Starr A (2005) Auditory brain-stem, middle- and long-latency evoked potentials in mild cognitive impairment. Clin Neurophysiol 116: 1918-1929. [Crossref]

75. Leuchter AF, Newton TF, Cook IANA, Walter DO, Rosenberg-Thompson S, et al. (1992) Changes in brain functional connectivity in Alzheimer-type and multi-infarct dementia. Brain 115: 1543-1561.

76. Rapoport SI, Horwitz B, Haxby JV, Grady CL (1986) Alzheimer's disease: metabolic uncoupling of associative brain regions. Can J Neurol Sci 13: 540-545. [Crossref]

77. Golubic SJ, Aine CJ, Stephen JM, Adair JC, Knoefel JE, et al. (2014) Modulatory role of the prefrontal generator within the auditory M50 network. NeuroImage 92: 120-131.

78. Green DL, Payne L, Polikar R, Moberg PJ, Wolk DA, et al. (2015) P50: A candidate ERP biomarker of prodromal Alzheimer's disease. Brain Res 1624: 390-397. [Crossref]

79. Golob EJ, Irimajiri R, Starr A (2007) Auditory cortical activity in amnestic mild cognitive impairment: relationship to subtype and conversion to dementia. Brain 130: 740-752.

80. Golob EJ, Johnson JK, Starr A (2001) Auditory event-related potentials during target detection are abnormal in mild cognitive impairment. Clin Neurophysiol 113: 151-161.

81. Cecchi M, Moore DK, Sadowsky CH, Solomon PR, Doraiswamy PM, et al. (2015) A clinical trial to validate event-related potential markers of Alzheimer's disease in outpatient settings. Alzheimers Dement (Amst) 1: 387-394.

82. Bennys K, Portet F, Touchon J, Rondouin G (2007) Diagnostic value of event-related evoked potentials N200 and P300 subcomponents in early diagnosis of Alzheimer's disease and mild cognitive impairment. J Clin Neurophysiol 24: 405-412.

83. Olichney JM, Morris SK, Ochoa C (2002) Abnormal verbal event related potentials in mild cognitive impairment and incipient Alzheimer's disease. J Neurol Neurosurg Psychiatry 73: 377-384.

84. Hillyard SA, Hink RF, Schwent VL, Picton TW (1973) Electrical signs of selective attention in the human brain. Science 182: 177-180.

85. Golob E, Starr A (2000) Age-related qualitative differences in auditory cortical responses during short-term memory. Clin Neurophysiol 111: 2234-2244.

86. Arnold SE, Hyman BT, Flory J, Damasio AR, Van Hoesen GW (1991) The topographical and neuroanatomical distribution of neurofibrillary tangles and neuritic plaques in the cerebral cortex of patients with Alzheimer's disease. Cereb Cortex 1: 103-116.

87. Yamaguchi S, Knight RT (1991) P300 generation by novel somatosensory stimuli. Electroencephalogr Clin Neurophysiol 78: 50-55.

88. Banquet JP, Guenther W, Smith M (1987) Probability processing in depressed patients. Electroencephalogr Clin Neurophysiol Suppl 40: 645-650.

89. Alho K (1995) Cerebral generators of mismatch negativity (MMN) and its magnetic counterpart (MMNm) elicited by sound changes. Ear Hear 16: 38-51.

90. Patel SH, Azzam PN (2005) Characterization of N200 and P300: selected studies of the Event-Related Potential. Int J Med Sci 2: 147-154. [Crossref]

91. Vecchio F, Määttä S (2011) The use of auditory event-related potentials in Alzheimer's disease diagnosis. Int J Alzheimers Dis 2011: 1-7.

92. Donchin E, Coles MG (1988) Is the P300 component a manifestation of context updating? Behav Brain Sci 11: 357.
93. Polich J, Corey-Bloom J (2005) Alzheimer's disease and P300: review and evaluation of task and modality. Curr Alzheimer Res 2: 515-525. [Crossref]

94. Duncan-Johnson CC, Donchin E (1982) The P300 component of the event-related brain potential as an index of information processing. Biol Psychol 14: 1-52

95. Ruchkin DS, Johnson R, Mahaffey D, Sutton S (1988) Toward a functional categorization of slow waves. Psychophysiology 25: 339-353.

96. Papaliagkas V, Kimiskidis V, Tsolaki M, Anogianakis G (2008) Usefulness of eventrelated potentials in the assessment of mild cognitive impairment. BMC Neurosci 9: 107.

97. Berger H (1929) Uber das elektroenkephalogramm des Menschen On the human electroencephalogram. Arch Psychiatr Nervenkr 87: 527-570.

98. Hughes SW, Crunelli V (2005) Thalamic mechanisms of EEG alpha rhythms and their pathological implications. Neuroscientist 11: 357-372.

99. Lorincz ML, Kékesi KA, Juhász G, Crunelli V, Hughes SW (2009) Temporal framing of thalamic relay-mode firing by phasic inhibition during the alpha rhythm. Neuron 63: 683-696.

100. Hindriks R, van Putten MJAM (2013) Thalamo-cortical mechanisms underlying changes in amplitude and frequency of human alpha oscillations. Neuroimage 70 150-163.

101. Bhattacharya BS, Coyle D, Maguire LP (2011) A thalamo-corticothalamic neural mass model to study alpha rhythms in Alzheimer's disease. Neural Netw 24: 631-645.

102. Pfurtscheller G, Stancák A, Jr, Neuper C (1996) Event-related synchronization (ERS) in the alpha band - an electrophysiological correlate of cortical idling: A review. Int J Psychophysiol 24: 39-46.

103. Klimesch W, Sauseng P, Hanslmayr S (2007) EEG alpha oscillations: the inhibitiontiming hypothesis. Brain Res Rev 53: 63-88. [Crossref]

104. Klimesch W (2012) $\alpha$-band oscillations, attention, and controlled access to stored information. Trends Cogn Sci 16: 606-617.

105. Haegens S, Nácher V, Luna R, Romo R, Jensen O (2011) $\alpha$-Oscillations in the monkey sensorimotor network influence discrimination performance by rhythmical inhibition of neuronal spiking. Proc Natl Acad Sci U S A 108: 19377-19382.

106. Haegens S, Händel BF, Jensen O (2011) Top-down controlled alpha band activity in somatosensory areas determines behavioral performance in a discrimination task. $J$ Neurosci 31: 5197-5204.

107. Mo J, Schroeder CE, Ding M (2011) Attentional modulation of alpha oscillations in macaque inferotemporal cortex. J Neurosci 31: 878-882.

108. Haegens S, Osipova D, Oostenveld R, Jensen O (2010) Somatosensory working memory performance in humans depends on both engagement and disengagement of regions in a distributed network. Hum Brain Mapp 31: 26-35.

109. Jones SR, Kerr CE, Wan Q, Pritchett DL, Hämäläinen M, et al. (2010) Cued spatia attention drives functionally relevant modulation of the mu rhythm in primary somatosensory cortex. $J$ Neurosci 30: 13760-13765.

110. Jensen O, Mazaheri A (2010) Shaping functional architecture by oscillatory alpha activity: gating by inhibition. Front Hum Neurosci 4: 186.

111. Hogan MJ, Swanwick GR, Kaiser J, Rowan M, Lawlor B (2003) Memory-related EEG power and coherence reductions in mild Alzheimer's disease. Int J Psychophysiol 49: 147-163. [Crossref]

112. Jiang ZY, Zheng LL (2006) Inter- and intra-hemispheric EEG coherence in patients with mild cognitive impairment at rest and during working memory task. $J$ Zhejiang Univ Sci B 7: 357-364.

113. Breslau J, Starr A, Sicotte N, Higa J, Buchsbaum MS (1989) Topographic EEG changes with normal aging and SDAT. Electroencephalogr Clin Neurophysiol 72: 281-289. [Crossref]

114. Peltz CB, Kim HL, Kawas CH (2010) Abnormal EEGs in cognitively and physically healthy oldest old: findings from the 90+ study. J Clin Neurophysiol 27: 292-295. [Crossref]

115. Oken BS, Kaye JA (1992) Electrophysiologic function in the healthy, extremely old Neurology. 42: 519-526.

116. Jiang ZY, Zheng LL, Yu EY (2008) EEG coherence characteristics at rest and during a three-level working memory task in normal aging and mild cognitive impairment. Med Sci Monit 14: 515-523. 
117. Zheng LL, Jiang ZY, Yu EY (2007) Alpha spectral power and coherence in the patients with mild cognitive impairment during a three-level working memory task. $J$ Zhejiang Univ Sci B 8: 584-592. [Crossref]

118. Fahimi G, Tabatabaei SM, Fahimi E, Rajebi H (2017) Index of Theta/Alpha Ratio of the Quantitative Electroencephalogram in Alzheimer's Disease: A Case-Control Study. Acta Med Iran 55: 502-506.

119. Allen KV, Frier BM, Strachan MW (2004) The relationship between type 2 diabetes and cognitive dysfunction: longitudinal studies and their methodological limitations. Eur J Pharmacol 490: 169-175. [Crossref]

120. Rondina R, Olsen RK, McQuiggan DA, Fatima Z, Li L, et al. (2016) Age-related changes to oscillatory dynamics in hippocampal and neocortical networks. Neurobiol Learn Mem 134: 15-30.

121. Moretti DV (2014) Alpha rhythm oscillations and MMSE scores are differently modified by transdermalor oral rivastigmine in patients with Alzheimer's disease. $A m$ J Neurodegener Dis 3: 72-83.

122. Calomeni MR, Furtado da Silva V, Velasques BB, Feijó OG, Bittencourt JM, et al (2017) Modulatory Effect of Association of Brain Stimulation by Light and Binaural Beats in Specific Brain Waves. Clin Pract Epidemiol Ment Health 13: 134-144.

123. Darvesh S, Hopkins DA (2003) Differential distribution of butyrylcholinesterase and acetylcholinesterase in the human thalamus. J Comp Neurol 11: 25-43.
124. Adler G, Brassen S, Chwalek K, Dieter B, Teufel M (2004) Prediction of treatment response to rivastigmine in Alzheimer's dementia. J Neurol Neurosurg Psychiatry 75: 292-294.

125. Moretti DV, Frisoni GB, Fracassi C, Pievani M, Geroldi C, et al. (2011) MCI patients' EEGs show group differences between those who progress and those who do not progress to AD. Neurobiol Aging 32: 563-571. [Crossref]

126. Abo Hagar A, AshourY, Abd El-Razek R, Elsamahy M, Shehab O (2018) Quantitative electroencephalographic changes and hippocampal atrophy in diabeti patients with mild cognitive impairment in Ismailia region. Egypt J Neurol Psychiatr Neurosurg 54: $1-15$

127. Nardone R, Sebastianelli L, Versace V, Saltuari L, Lochner P, et al. (2018) Usefulness of EEG Techniques in Distinguishing Frontotemporal Dementia from Alzheimer's Disease and Other Dementias. Dis Markers 2018: 6581490

128. Payne L, Sekuler R (2014) The importance of ignoring: Alpha oscillations protect selectivity. Curr Dir Psychol Sci 23: 171-177.

129. Park H, Lee DS, Kang E, Kang H, Hahm J, et al. (2014) Blocking of irrelevant memories by posterior alpha activity boosts memory encoding. Hum Brain Mapp 35: 3972-3987.

130. Payne L, Guillory S, Sekuler R (2013) Attention-modulated alpha-band oscillations protect against intrusion of irrelevant information. J Cogn Neurosci 25: $1463-1476$

Copyright: (2019 Miranda P. This is an open-access article distributed under the terms of the Creative Commons Attribution License, which permits unrestricted use, distribution, and reproduction in any medium, provided the original author and source are credited. 